\title{
Utility of Transesophageal Echocardiography in the Identification and Treatment of Occult Mechanisms of Cerebral Infarction
}

\section{Mark Evan Heslin ( $\square$ heslinm6@rowan.edu )}

Cooper Medical School of Rowan University: Rowan University Cooper Medical School https://orcid.org/0000-0002-7895-7780

Jesse M. Thon

Cooper University Health Care

\section{Evan Caruso}

Cooper University Health Care

\section{Prasanth Romiyo}

Cooper Medical School of Rowan University: Rowan University Cooper Medical School

\section{Ankit Rana}

Cooper Medical School of Rowan University: Rowan University Cooper Medical School

\section{Siyuan Yu}

Cooper Medical School of Rowan University: Rowan University Cooper Medical School

\section{Lauren Thau}

Cooper Medical School of Rowan University

\section{Ameena Rana}

Cooper Medical School of Rowan University: Rowan University Cooper Medical School James E. Siegler

Cooper University Health Care

\section{Original Article}

Keywords: cryptogenic stroke, embolic stroke of undetermined source, transesophageal echocardiography, ischemic stroke

Posted Date: February 9th, 2021

DOl: https://doi.org/10.21203/rs.3.rs-179879/v1

License: (c) (1) This work is licensed under a Creative Commons Attribution 4.0 International License. Read Full License 
Version of Record: A version of this preprint was published at Journal of Clinical Neuroscience on January 1st, 2022. See the published version at https://doi.org/10.1016/j.jocn.2021.10.020. 


\section{Abstract}

\section{Purpose}

To evaluate the diagnostic utility of TEE in identifying cardiac sources of embolism (CSE) in cryptogenic stroke patients and to determine whether the identification of these CSE results in clinically significant management changes.

Methods

A prospective registry of consecutively admitted patients with acute ischemic stroke (1/1/20158/10/2020) was retrospectively queried. Patients 18 to 60 years of age with stroke due to mechanisms other than large or small vessel disease, or atrial fibrillation were eligible for inclusion. The primary outcome was any high-risk CSE identified on TEE following unrevealing TTE. Secondary outcomes included a composite of individual CSEs and subsequent management changes.

Results

Of the 2,404 consecutive stroke patients evaluated during the study period, $263(11 \%)$ met inclusion criteria; 103 (39\%) were women and the median age was 53 (IQR 46-57). TEE was performed in 108 patients (41\%). A high-risk CSE was identified in 36 patients (33\%), the majority of which were PFOs $(n=29)$. TEE led to a clinical management change in 14 patients $(39 \%)$ after identification of a high-risk CSE; 6 underwent PFO closure and 8 had adjustment to their antithrombotic therapy.

Conclusion

In our single-center study of cryptogenic stroke patients, the addition of TEE to the comprehensive stroke evaluation led to the identification of a high-risk CSE in one in three patients resulting in significant management changes. Most high-risk CSEs were PFOs, which likely underestimates the likelihood of management change given the publication of successful PFO closure trials in the middle of our study period.

\section{Background}

Cryptogenic stroke comprises approximately $25 \%$ of all patients with ischemic stroke [1], with an annualized risk of recurrence between 5-7\% [2,3]. Although the clinical construct of embolic stroke of undetermined source (ESUS) was introduced in 2014 to better define this population of stroke patients (1), the heterogeneity of the condition likely explains why a single targeted treatment is no more advantageous than aspirin and risk-factor modification [2, 3].

Following a standard ischemic stroke evaluation for large artery atherosclerotic disease, small vessel disease, and cardioembolism with an electrocardiogram (ECG), 24-hour cardiac rhythm monitoring, a transthoracic echocardiogram (TTE), and CT or MR angiography [4], a substantial proportion of patients 
have no identifiable source of cerebral embolism. The best available evidence suggests that the most common occult mechanisms of ESUS include non-stenotic atherosclerotic disease in $20-30 \%$ of patients [5], paroxysmal atrial fibrillation in $10-20 \%$ of patients [6], suspected atrial cardiopathy without atrial fibrillation (AF) or atrial flutter [7], occult thrombophilia, and other mechanisms. Among these less common etiologies of ESUS, patent foramen ovale (PFO), valvular disease, aortic arch atheroma, and intracardiac thrombus are better visualized using transesophageal echocardiography (TEE) when compared to transthoracic echocardiography (TTE) [8]. Awareness of each of these sources of embolism has the potential to influence clinical management-with unique treatment recommendations-which can reduce the risk of subsequent cerebrovascular events. Additionally, recognition of these occult sources of cardiac embolism can provide clarity to patients regarding their stroke mechanism and risk of recurrence, as well as deter unnecessary additional testing for other stroke etiologies.

In the present investigation, we sought to confirm the increased diagnostic yield of TEE in patients with cryptogenic stroke, describe relevant echocardiographic findings, and to determine whether TEE, in addition to routine TTE, is associated with changes in clinical management.

\section{Methods}

\section{Study Design and Participants}

We retrospectively queried a prospectively maintained registry of consecutively admitted patients with acute ischemic stroke 18 to 60 years of age at Cooper University Hospital (CUH) from January 1, 2015 to August 10, 2020 and supplemented these data with review of electronic medical records and imaging studies. Patients were excluded from the analysis if they opted to receive comfort care during the index hospitalization. Stroke etiology was classified according to the modified Trial of Org 10172 Acute Stroke Trial criteria [9] and patients with strokes due to large or small vessel disease, or AF were excluded from the study. For the purposes of this investigation, patients with PFO, aortic arch atheroma $>4 \mathrm{~mm}$ or ulcerated plaque, aortic arch thrombus, or left atrial enlargement of any severity were classified as having a cryptogenic infarction. Patients with paroxysmal AF identified on subsequent outpatient telemetry were classified as having a cryptogenic infarction during their index hospitalization. Patients with multiple possible etiologies of stroke were included if a non-AF cardioembolic source (e.g., severe systolic dysfunction with ejection fraction $<40 \%$, left ventricular thrombus, endocarditis) were identified. To optimize sensitivity of capturing relevant TEE findings, and because TEE findings could have contributed to a classification of stroke mechanism as cardioembolic, patients with non-AF CSE and cryptogenic stroke were consolidated into a single patient group for all analyses. Furthermore, the designation of stroke mechanism as cryptogenic or cardioembolic in patients with severe systolic dysfunction, PFO, or other intracardiac pathologies or variants remains controversial [10-12]; therefore, suspected non-AF CSE and cryptogenic patients were consolidated. (Subgroup analyses of findings based on non-AF CSE and cryptogenic stroke are also presented for the sake of transparency.) At our center, each TEE is first interpreted by a senior cardiology fellow using standard TEE windows, and then confirmed by a boardcertified cardiologist. The use of agitated saline or Definity ${ }^{\circledR}$ contrast was made at the discretion of the 
cardiology attending. Abnormalities including PFO (identified by color flow doppler, visual examination, and/or agitated saline injection in the bicaval view), left atrial appendage thrombus or spontaneous echo contrast, mobile or aneurysmal interatrial septum, grade IV or greater atheroma of the aortic arch, valvular pathology including stenosis, regurgitation or vegetation, visible thrombus, and ejection fraction (measured in the transgastric short axis view) were identified. Echocardiographic findings were abstracted from the medical record, confirmed by the secondary read (EC), and then included in the study analysis. At our center, transcranial doppler with agitated saline is not routinely performed to evaluate for PFO as it cannot identify other CSE such as valvular disease, intracardiac thrombus, aortic arch plaque, or other pathologies. Acute ischemic stroke was diagnosed clinically by a vascular neurologist or if there was radiographic evidence of acute infarction on unenhanced computed tomography (CT) or diffusionweighted imaging magnetic resonance imaging (DWI-MRI). Infarctions were categorized as cortical, subcortical/infratentorial, and/or involving multiple vascular distributions based on CT and/or MRI findings. Subcortical/infratentorial infarctions were documented if their maximal diameter exceeded $1.5 \mathrm{~cm}$ or if there were multiple, and therefore could not be categorized as lacunar infarcts.

\section{Data Collection}

The baseline demographics, comorbidities, National Institutes of Health Stroke Scale (NIHSS) scores, imaging characteristics, high-risk cardiac sources of embolism (CSEs) on TEE, cardiac event monitoring data, and clinical management changes were captured among included patients. High-risk CSEs were defined as cardiac abnormalities or variants that have been previously associated with stroke etiology in otherwise cryptogenic stroke and included PFO, atrial septal aneurysm (ASA), aortic arch atheroma > $4 \mathrm{~mm}$ and/or ulceration [13], valvular lesion(s), intracardiac tumors, and intracardiac thrombus. Excess atrial mobility (5-10 mm atrial excursion) was also captured, but was not considered a singular high-risk CSE unless it occurred in conjunction with a PFO. Subsequent cerebrovascular events were also evaluated, including recurrent ischemic stroke, hemorrhagic stroke, or death. Cardiac event monitoring data were obtained from Holter monitor and implantable loop recorder (ILR) interrogation reports.

\section{Statistical Analysis}

Descriptive statistics were used to summarize continuous and categorical variables. Continuous variables were reported as medians with interquartile range or means with standard deviation. Chisquared test was used for between-group comparisons for categorical data, or Fisher's exact test when the contingency table cell counts were less than five. The Wilcoxon Rank-Sum test was used for betweengroup comparisons of continuous variables. The primary outcome was any high risk CSE identified on TEE but not TTE. Secondary outcomes included a composite of non-PFO CSE and each individual source of cardiac embolism on TEE, as well as specific management changes at any time point following TEE and only attributed to TEE findings (or lack of findings). Prespecified management changes included PFO closure, escalation to dual antithrombotic therapy, or use of therapeutic anticoagulation. Logistic regression was used to estimate the association between clinical and radiographic findings with the presence of a high-risk CSE, with adjustment for all variables significant to $p</=0.1$. Logistic regression was also used to estimate the odds of being recommended for a TEE versus not, with adjustment for all 
variables significant to $p \leq 0.1$. Time to management change in patients with CSE on TEE was evaluated using Kaplan-Meier survival curves, with comparisons made between PFO and non-PFO CSE using a logrank test of equality. No adjustments were made due to low event rates.

All tests were performed at the two-sided level with an alpha of 0.05, using STATA v15.0 (College Station, TX). Missing data were minimal and not imputed. All analyses were considered exploratory, therefore no adjustments were made for multiple comparisons. P-values were provided for convenience and should be interpreted with caution. This study was approved by the local institutional review board.

\section{Results}

Of the 2,404 consecutive adult patients with acute ischemic stroke evaluated during the study period, 263 met inclusion criteria (Fig. 1, Table 1) and were followed for a median of 12.8 months (IQR 3.5-28.9 months) after admission for stroke. Among included patients, 133 (51\%) were ordered for a TEE due to concern for an occult CSE. Generally, younger patients and patients with fewer vascular risk factors were recommended for a TEE (Supplementary Table 1). After adjustment for all predictors of TEE being ordered ( $p \leq 0.1)$, only younger age (aOR 0.96 per year, $95 \% \mathrm{Cl} 0.93-0.99, p=0.010)$ and stroke affecting multiple vascular territories (aOR $1.84,95 \% \mathrm{Cl} 1.01-3.36, \mathrm{p}=0.046)$ were independently associated with a TEE order. 
Table 1

Demographic Data.

\begin{tabular}{|c|c|}
\hline & All included patients $(n=263)$ \\
\hline Age, median (IQR) & $53(46-57)$ \\
\hline Female sex, no. (\%) & $103(39)$ \\
\hline \multicolumn{2}{|l|}{ Race, no. (\%) } \\
\hline White & $123 / 227(55)$ \\
\hline Black & $83 / 227(37)$ \\
\hline Asian & 6/227 (3) \\
\hline Other & $14 / 227(6)$ \\
\hline Hispanic, no. (\%) & $43 / 239(18)$ \\
\hline \multicolumn{2}{|l|}{ Primary insurance provider, no. (\%) } \\
\hline None & $34 / 261(13)$ \\
\hline Medicaid & $91 / 261(35)$ \\
\hline Medicare & $45 / 261(17)$ \\
\hline Private/Other & $91 / 261(35)$ \\
\hline \multicolumn{2}{|l|}{ Medical history, no. (\%) } \\
\hline Hypertension & $182(69)$ \\
\hline Tobacco use & $94 / 260(36)$ \\
\hline Diabetes mellitus & $99(38)$ \\
\hline Dyslipidemia & $102(39)$ \\
\hline Coronary artery disease & $34(13)$ \\
\hline Congestive heart failure & $19(7)$ \\
\hline Prior stroke & $49(19)$ \\
\hline Peripheral artery disease & $5(2)$ \\
\hline Baseline NIHSS, median (IQR) & $5(2-10)$ \\
\hline LVO, no. (\%) & $36(14)$ \\
\hline Ejection fraction, median \% (IQR) & $55(55-60)$ \\
\hline Ejection fraction < $40 \%$, no. (\%) & $26(10)$ \\
\hline
\end{tabular}




\begin{tabular}{|ll|}
\hline & All included patients $(\mathbf{n = 2 6 3 )}$ \\
\hline HCT or MRI findings, no. (\%) & \\
\hline Cortical infarction & $167(64)$ \\
\hline Infratentorial infarction & $94(36)$ \\
\hline Infarction in > 1 vascular territory & $63(24)$ \\
\hline
\end{tabular}

\section{TEE findings}

A TEE was ultimately performed in 108 patients (81\% of those with orders), the majority of which were performed during the hospitalization for stroke (Table 2). A high-risk CSE was identified in 36 patients $(33 \%)$, the majority of which were PFOs $(n=29$; Table 2$)$. All patients with an ASA had an associated PFO, while 2 of 5 patients with excess atrial mobility had an associated PFO. Four patients had high-risk valvular lesions (all involving the aortic valve), including 1 patient with marantic endocarditis (Fig. 2), 1 patient with a degenerated/ruptured leaflet, 1 with heavy calcification, and 1 with significant Lambl's excrescence. Three patients had aortic arch plaque $>4 \mathrm{~mm}$ in thickness with or without ulceration, and 1 patient had a left atrial appendage thrombus (without AF). One-hundred eight patients (41\%) underwent outpatient cardiac event monitoring, 56 of whom had also undergone TEE. Abnormalities on outpatient event monitoring were captured in 11 patients (8 with AF, 1 sinus bradycardia, 1 atrial bigeminy, 1 2nd degree AV block). Of the 8 patients who were found to have paroxysmal atrial fibrillation, only 1 had a CSE on TEE, which was a PFO. Detailed results for event monitoring and left atrial morphology are being reported separately. 
Table 2

TEE data and findings.

\begin{tabular}{|ll|}
\hline & All included patients $(\mathbf{n}=\mathbf{2 6 3})$ \\
\hline TEE ordered, no. $(\%)$ & $133(51)$ \\
\hline TEE performed, no. $(\%)$ & $108 / 133(81)$ \\
\hline TEE performed during hospitalization, no. $(\%)$ & $105 / 123(86)$ \\
\hline TEE performed after discharge & $3 / 10(30)$ \\
\hline Time from admission to TEE, median days (IQR) \\
\hline All patients & $3(2-5)(\mathrm{n}=108)$ \\
\hline Inpatient TEEs & $3(2-5)(\mathrm{n}=105)$ \\
\hline Outpatient TEEs & $12(12-125)(\mathrm{n}=3)$ \\
\hline High-risk CSE on TEE*, no. (\%) & $36 / 108(33)$ \\
\hline PFO & $29 / 108(27)$ \\
\hline ASA & $5 / 108(5)$ \\
\hline PFO + ASA & $5 / 108(5)$ \\
\hline Intracardiac thrombus & $1 / 108(1)$ \\
\hline Valvular abnormality* & $4 / 108(4)$ \\
\hline Intracardiac tumor & $0 / 108(0)$ \\
\hline Aortic arch plaque $>4 m m$ and/or ulcerated & $3 / 108(3)$ \\
\hline ROPE score, median (IQR) & $5(4-6)(\mathrm{n}=108)$ \\
\hline
\end{tabular}

Predictors of high-risk CSE on TEE

There was no association between higher Risk of Paradoxical Embolism (ROPE) score [14] and a highrisk CSE on TEE (Table 3) or with a PFO (OR 1.22, 95\% Cl 0.94-1.58, $\mathrm{p}=0.14)$. In unadjusted regression, high-risk CSE was significantly associated with lower National Institutes of Health Stroke Scale $(\beta=-0.02$, $95 \% \mathrm{Cl}-0.03-0.004, \mathrm{p}=0.01)$, lack of proximal intracranial occlusion (OR $0.13,95 \% \mathrm{Cl} 0.02-1.03, p=$ $0.054)$, and no prior tobacco use (OR $4.10,95 \% \mathrm{Cl} 1.52-11.08, \mathrm{p}=0.005)$, while there was a trend toward a relationship with a history of no dyslipidemia (OR $0.49,95 \% \mathrm{Cl} 0.21-1.15, \mathrm{p}=0.10)$. After entering each of these variables into a multivariable model, tobacco use (aOR $0.16,95 \% \mathrm{Cl} 0.05-0.49, \mathrm{p}=0.005)$ and history of dyslipidemia (aOR $0.27,95 \% \mathrm{Cl} 0.10-0.73, \mathrm{p}=0.009$ ) were strongly and inversely associated with a high-risk CSE on TEE, while lower NIHSS trended toward an association with high-risk CSE (aOR 0.92 per point, $95 \% \mathrm{Cl} 0.83-1.01, \mathrm{p}=0.094$; Table 3 ). 
Table 3

Independent predictors of high-risk CSE.

\begin{tabular}{|c|c|c|c|c|c|c|c|}
\hline & $\begin{array}{l}\text { No high-risk } \\
\text { CSE on TEE } \\
(n=72)\end{array}$ & $\begin{array}{l}\text { High-risk } \\
\text { CSE* on } \\
\text { TEE } \\
(n=36)\end{array}$ & $\begin{array}{l}\mathrm{p}- \\
\text { value }\end{array}$ & $\begin{array}{l}\text { Unadjusted } \\
\text { OR (95\%Cl) }\end{array}$ & $\begin{array}{l}\text { p- } \\
\text { value }\end{array}$ & $\begin{array}{l}\text { Adjusted } \\
\text { OR } \\
(95 \% \mathrm{Cl})\end{array}$ & $\begin{array}{l}\mathrm{p} \text { - } \\
\text { value }\end{array}$ \\
\hline $\begin{array}{l}\text { Age, median } \\
\text { (IQR) }\end{array}$ & $51(43-56)$ & $\begin{array}{l}50(44- \\
57)\end{array}$ & 0.97 & $\begin{array}{l}-0.001 * \\
(-0.01- \\
0.01)\end{array}$ & 0.92 & & \\
\hline $\begin{array}{l}\text { Female sex, no. } \\
(\%)\end{array}$ & $29(40)$ & $15(42)$ & 0.89 & $\begin{array}{l}1.06 \\
(0.47- \\
2.39)\end{array}$ & 0.89 & & \\
\hline $\begin{array}{l}\text { White race, no. } \\
(\%)\end{array}$ & 33/63 (52) & $\begin{array}{l}20 / 31 \\
(65)\end{array}$ & 0.27 & $\begin{array}{l}1.65 \\
(0.68- \\
4.01)\end{array}$ & 0.27 & & \\
\hline $\begin{array}{l}\text { Hispanic, no. } \\
(\%)\end{array}$ & 13/63 (21) & 6/35 (17) & 0.68 & $\begin{array}{l}0.80 \\
(0.27- \\
2.32)\end{array}$ & 0.68 & & \\
\hline \multicolumn{8}{|l|}{$\begin{array}{l}\text { Medical history, } \\
\text { no. }(\%)\end{array}$} \\
\hline Hypertension & $49(68)$ & $21(58)$ & 0.32 & $\begin{array}{l}0.66 \\
(0.29- \\
1.50)\end{array}$ & 0.32 & & \\
\hline $\begin{array}{l}\text { Prior tobacco } \\
\text { use }\end{array}$ & 32/71 (45) & 6/36 (17) & $\begin{array}{l}<.01 \\
0.01\end{array}$ & $\begin{array}{l}0.24 \\
(0.09- \\
0.66)\end{array}$ & $\begin{array}{l}<.01 \\
0.01\end{array}$ & $\begin{array}{l}0.16 \\
(0.05- \\
0.49)\end{array}$ & $\begin{array}{l}<.01 \\
0.01\end{array}$ \\
\hline $\begin{array}{l}\text { Diabetes } \\
\text { mellitus }\end{array}$ & $25(35)$ & $11(31)$ & 0.67 & $\begin{array}{l}0.83 \\
(0.35- \\
1.95)\end{array}$ & 0.67 & & \\
\hline Dyslipidemia & $34(47)$ & $11(31)$ & 0.15 & $\begin{array}{l}0.49 \\
(0.21- \\
1.15)\end{array}$ & 0.1 & $\begin{array}{l}0.27 \\
(0.10- \\
0.73)\end{array}$ & $\begin{array}{l}<.01 \\
0.01\end{array}$ \\
\hline $\begin{array}{l}\text { Coronary artery } \\
\text { disease }\end{array}$ & $8(11)$ & $5(14)$ & 0.68 & $\begin{array}{l}1.29 \\
(0.39- \\
4.27)\end{array}$ & 0.68 & & \\
\hline $\begin{array}{l}\text { Congestive } \\
\text { heart failure }\end{array}$ & $6(8)$ & $1(3)$ & 0.42 & $\begin{array}{l}0.31 \\
(0.04- \\
2.72)\end{array}$ & 0.29 & & \\
\hline Prior stroke & $9(13)$ & $7(20)$ & 0.34 & $\begin{array}{l}1.69 \\
(0.57- \\
4.98)\end{array}$ & 0.34 & & \\
\hline $\begin{array}{l}\text { Peripheral artery } \\
\text { disease }\end{array}$ & $1(1)$ & $1(3)$ & 1 & $\begin{array}{l}2.03 \\
(0.12- \\
33.40)\end{array}$ & 0.62 & & \\
\hline
\end{tabular}




\begin{tabular}{|c|c|c|c|c|c|c|c|}
\hline & $\begin{array}{l}\text { No high-risk } \\
\text { CSE on TEE } \\
(n=72)\end{array}$ & $\begin{array}{l}\text { High-risk } \\
\text { CSE* on } \\
\text { TEE } \\
(n=36)\end{array}$ & $\begin{array}{l}\mathrm{p}- \\
\text { value }\end{array}$ & $\begin{array}{l}\text { Unadjusted } \\
\text { OR (95\%Cl) }\end{array}$ & $\begin{array}{l}\mathrm{p}- \\
\text { value }\end{array}$ & $\begin{array}{l}\text { Adjusted } \\
\text { OR } \\
(95 \% \mathrm{Cl})\end{array}$ & $\begin{array}{l}\mathrm{p}- \\
\text { value }\end{array}$ \\
\hline $\begin{array}{l}\text { Baseline NIHSS, } \\
\text { median (IQR) }\end{array}$ & $5(2-12)$ & $3(1-6)$ & 0.01 & $\begin{array}{l}-0.02^{\star} \\
(-0.03- \\
-0.004)\end{array}$ & 0.01 & $\begin{array}{l}0.92 \\
(0.83- \\
1.01)\end{array}$ & 0.09 \\
\hline LVO, no. (\%) & $13(18)$ & $1(3)$ & 0.03 & $\begin{array}{l}0.13 \\
(0.02- \\
1.03)\end{array}$ & 0.05 & $\begin{array}{l}0.20 \\
(0.02- \\
2.02)\end{array}$ & 0.17 \\
\hline $\begin{array}{l}\text { Ejection } \\
\text { fraction }<40 \% \text {, } \\
\text { no. }(\%)\end{array}$ & $7(10)$ & $2(6)$ & 0.72 & $\begin{array}{l}0.55 \\
(0.11- \\
2.77)\end{array}$ & 0.47 & & \\
\hline \multicolumn{8}{|l|}{$\begin{array}{l}\text { HCT or MRI } \\
\text { findings, no. (\%) }\end{array}$} \\
\hline $\begin{array}{l}\text { Cortical } \\
\text { infarction }\end{array}$ & $45(63)$ & $24(67)$ & 0.67 & $\begin{array}{l}1.20 \\
(0.52- \\
2.78)\end{array}$ & 0.67 & & \\
\hline $\begin{array}{l}\text { Infratentorial } \\
\text { infarction }\end{array}$ & $27(38)$ & $12(33)$ & 0.67 & $\begin{array}{l}0.83 \\
(0.36- \\
1.93)\end{array}$ & 0.67 & & \\
\hline $\begin{array}{l}\text { Infarction in >1 } \\
\text { vascular } \\
\text { territory }\end{array}$ & $20(28)$ & $11(31)$ & 0.76 & $\begin{array}{l}1.14 \\
(0.48- \\
2.75)\end{array}$ & 0.76 & & \\
\hline $\begin{array}{l}\text { ROPE score, } \\
\text { median (IQR) }\end{array}$ & $6(4-7)$ & $6(5-7)$ & 0.25 & $\begin{array}{l}1.16 \\
(0.91- \\
1.48)\end{array}$ & 0.23 & & \\
\hline
\end{tabular}

\section{Management changes following TEE}

TEE led to a significant change in the secondary stroke prevention strategies for 14 patients with a highrisk CSE and 6 patients without an identifiable CSE (Fig. 1). Of the 14 patients with management changes following identification of a high-risk CSE, 12 had a PFO- 6 of whom underwent closure, 4 were anticoagulated ( 2 of whom also had a lower extremity deep vein thrombosis), and 2 were switched from single to dual antiplatelet therapy. The 2 additional patients with management changes had valvular lesions; 1 was anticoagulated and 1 was switched from single to dual antiplatelet therapy. Time to any management change was significantly more delayed in patients who underwent PFO closure versus any other change in management (unadjusted $p=0.001$ by log-rank, Fig. 3). All PFO closures took place in the year 2017 or subsequent years, after publication of trials demonstrating superiority of closure [15-17]. Of the 6 patients with PFO who were treated with escalation of antithrombotic therapy (Fig. 1), 3 were given this recommendation after the publication of successful PFO closure trials in 2017 after a risk/benefit discussion of treatment options with either the patient's primary cardiologist or neurologist. The most 
common reason for deferral of PFO closure in 23 patients with a PFO was loss to follow-up $(n=6)$, anticoagulation pursued in lieu of closure $(n=4)$, and PFO considered too small ( $n=4$; Supplementary Table 4). None of the antithrombotic adjustments reported here were recommended on the basis of findings from outpatient cardiac event monitoring.

\section{Discussion}

In this single-center observational cohort study of young-to-middle aged stroke patients with mechanisms that could not be attributed to AF, large vessel stenosis, or small vessel disease, the addition of a TEE to a comprehensive stroke evaluation resulted in a high probability of identifying an occult, high-risk CSE and subsequent change in management. One in three patients in this cohort who underwent TEE were found to have cardiac abnormalities which could have led to changes in secondary stroke prevention. Interestingly, only 6 of 29 patients with a PFO underwent PFO closure, despite the fact that half of the included patients in this cohort were admitted following publication of seminal PFO closure trials [15-17] demonstrating superiority of this intervention to medical management. More than half of patients who did not undergo PFO closure either failed to follow-up in outpatient clinic-which is a common concern with the population in our region-were thought to have a PFO too small to intervene upon, or were empirically anticoagulated based on a risk-benefit discussion with the patient's neurologist and/or cardiologist.

The majority of non-lacunar strokes are embolic in nature and in this young cohort of stroke patients, cardiac and arterial sources are the most likely origin of embolus [1], therefore structural cardiac imaging must be obtained. Compared to TTE, TEE has been shown to have higher sensitivity for characterizing aortic arch plaque thickness and mobility, visualization of the left atrial appendage, detecting infectious, marantic, or neoplastic valvular lesions, and identifying the presence and size of a PFO with associated high-risk features (e.g., atrial septal aneurysm) [8]. The diagnostic utility of TEE was further confirmed in our study by identifying a CSE in $33 \%$ of patients without a known stroke mechanism. Of those patients, most had a PFO. Unsurprisingly, in this saturated sample of young patients with frequent cortical strokes, few vascular risk factors, and no other traditional stroke mechanism on etiologic workup, the average Risk of Paradoxical Embolism (ROPE) score was high-indicating a high attributable risk of stroke to a potential PFO if identified. As the ROPE score essentially serves as an inverse indicator of comorbid vascular disease, it is intuitive that the ROPE score could be repurposed to predict the presence and attributable risk of stroke to many types of high-risk CSEs (other than PFO).

Also unsurprising was the overall low proportion of patients with proximal large vessel occlusion. Despite the high number of patients with cortical infarcts, most strokes were only mild-to-moderate in severity with only 1 in 7 patients having a proximal LVO. These data are consistent with previously published literature indicating that emboli from these high-risk CSEs (largely PFOs) may be physiologically distinct from emboli due to AF or cervicocephalic atherosclerotic disease. According to several observational studies involving cryptogenic or cardioembolic stroke populations, patients with PFO have generally 
milder presenting deficits and less frequent intracranial occlusions when compared to patients without PFO, or with other sources of cardiac embolism (e.g., AF) [18-20].

The vast majority of patients in our study had a TEE performed during the hospitalization for the index event, with a change in medical management occurring much sooner compared to PFO closure in patients with high-risk CSE. This is not surprising since secondary stroke prevention strategies in PFO management mitigate long-term risk of a small magnitude over several years (3-6 years) [15-17], with preliminary PFO closure trials failing to demonstrate efficacy after short-term follow-up (2-4 years) [2122]. In contrast to the low annualized risk of recurrent stroke with PFO $(\sim 1 \% / \mathrm{yr})$, the risk of recurrent stroke is far greater in patients with valvular lesions [23] and aortic arch plaque (2-4\%/yr) [13]. Therefore, earlier and more aggressive medical management may be indicated. Additionally, almost half of our patients were evaluated in the era prior to the publication of successful PFO closure trials in 2017 [1517]. Therefore, the proportion of patients with management changes following TEE is likely an underestimation of potential beneficiaries with this intervention. Furthermore, inclusion of patients before 2019 likely explained why 6 patients with normal TEE findings were empirically anticoagulated for cryptogenic stroke. All but one of these patients were anticoagulated prior to publication of two randomized clinical trials which failed to demonstrate superiority of anticoagulation with rivaroxaban [2] or dabigatran [3] over aspirin in ESUS.

Prior to our study, there has been limited data evaluating the impact of TEE on clinical management following cryptogenic stroke. One retrospective cohort study of 263 patients with cryptogenic stroke reported that TEE identified a potential etiology of stroke in approximately $42 \%$ of patients-similar to the $33 \%$ who underwent TEE in this cohort-however only 1 patient $(0.4 \%)$ had a management change [24]. This contrasts with our experience in which a tenfold higher proportion of patients had a management change following TEE. Larger cohorts representing more diverse populations and institutional experiences are called upon to validate these findings.

\section{Limitations}

This study represents the observational experience of a single, tertiary-care referral center over a 5-year period and is limited by its small sample size, retrospective nature, and loss to follow-up. Our Comprehensive Stroke Center is located in an underserved community with many patients of low socioeconomic status and this could discourage providers from ordering outpatient TEEs due to the concern for a low likelihood of follow up in outpatient clinic. However, we observed no significant impact between insurance status and recommendation for TEE in this population (Supplementary Table 1). The only independent predictors of TEE being clinically recommended in this cohort were younger age and presence of infarcts spanning multiple vascular territories.

Although TEE facilitated the recognition of high-risk CSE in a large proportion of patients without an identifiable cause of stroke, this study was underpowered to determine whether such information led to actionable changes that would reduce the risk of secondary events. Recurrent events in this population, 
stratified by assessment with and findings from outpatient cardiac event monitoring and structural cardiac abnormalities (e.g., left atrial diameter), are being reported in detail separately. That said, larger, multicenter randomized clinical trials and meta-analyses have demonstrated that PFO closure [15-17], anticoagulation [25], and dual antithrombotic therapy with high-intensity statin [13], are superior to conventional medical management for secondary stroke prevention in at-risk patients.

It is important to recognize that TEE is not a procedure without risk [26], and that transcranial doppler with agitated saline has a similar sensitivity and specificity to TEE for detecting a right-to-left shunt [27]. However, based on data from this saturated cohort of young patients without a known cause of strokeand therefore a high suspicion of occult CSE, TEE led to the recognition of high-risk CSEs other than PFO in $6 \%$ of tested patients $(n=7 / 108)$ who had otherwise unremarkable TTEs. Therefore, we would argue that TCD with agitated saline could be useful as a safe screening tool for right-to-left shunt, but a normal $\mathrm{TCD} /$ saline study should not obviate the need (or advantage) of TEE.

\section{Conclusion}

One in five patients with acute stroke experience ESUS despite a complete workup with non-invasive imaging. However, randomized clinical trials have shown no advantage of therapeutic anticoagulation over aspirin for secondary stroke prevention [2,3]. This is largely due to the heterogeneity of patients with ESUS and multitudinous mechanisms at play (e.g., PFO, non-stenotic carotid plaque, aortic arch atheroma, paroxysmal AF). The lack of equipoise for a "universal" secondary prevention strategy emphasizes the importance of an advanced diagnostic assessment in these patients to identify the source of embolism and provide targeted treatment. In our cohort, we found a significant advantage of TEE when added to TTE for identifying a high-risk CSE. Furthermore, these findings led to management changes for a significant number of imaged patients. Our results encourage the regular use of TEEs in young, cryptogenic stroke patients, especially in the inpatient setting, since TEE can identify a CSE that leads to immediate antithrombotic therapy change prior to discharge in a small proportion of patients at high risk for recurrent events. Whether the addition of TEE to the standard stroke diagnostic battery results in a meaningful reduction in recurrent strokes can only be determined in larger studies, or with pooling of these data with the published literature.

\section{Declarations}

Funding: No funding.

Conflicts of interest/Competing interests: Conflict of Interest: The authors declare that they have no conflict of interest.

Availability of data and material (data transparency): All data and materials support the authors published claims and comply with field standard. 
Code availability (software application or custom code): All software application and custom code support the authors published claims and comply with field standard.

Authors' contributions: All authors contributed to the study conception and design. Material preparation, data collection and analysis were performed by Mark Heslin, Jesse Thon, James Siegler, Evan Caruso, Lauren Thau, Ankit Rana, Siyuan Yu, Prasanth Romiyo, and Ameena Rana. The first draft of the manuscript was written by Mark Heslin and all authors commented on previous versions of the manuscript. All authors read and approved the final manuscript.

\section{References}

1. Hart RG, Diener HC, Coutts SB, et al (2014) Cryptogenic Stroke/ESUS International Working Group. Embolic strokes of undetermined source: the case for a new clinical constrict. Lancet Neurol 13:429438.

2. Hart RG, Sharma M, Hundl H, et al (2018) Rivaroxaban for Stroke Prevention after Embolic Stroke of Undetermined Source. N Engl J Med 378:2191-2201.

3. Diener HC, Sacco RL, Easton JD, et al (2019) Dabigatran for Prevention of Stroke after Embolic Stroke of Undetermined Source. N Engl J Med 380:1906-1917.

4. Powers WJ, Rabinstein AA, Ackerson T, et al (2019) Guidelines for the Early Management of Patients With Acute Ischemic Stroke: 2019 Update to the 2018 Guidelines for the Early Management of Acute Ischemic Stroke: A Guideline for Healthcare Professionals From the American Heart Association/American Stroke Association. Stroke 50:344-418.

5. Siegler JE, Thon JM, Woo JH, et al (2019) Prevalence of Nonstenotic Carotid Plaque in Stroke Due to Atrial Fibrillation Compared to Embolic Stroke of Undetermined Source. J Stroke Cerebrovasc Dis 28:104289.

6. Favilla CG, Ingala E, Jara J, et al (2015) Predictors of finding occult atrial fibrillation after cryptogenic stroke. Stroke 46:1210-1215.

7. Kamel H, Okin PM, Longstreth WT, et al (2015) Atrial Cardiopathy: A Broadened Concept of Left Atrial Thromboembolism Beyond Atrial Fibrillation. Future Cardiol 11:323-331.

8. Nakanishi K, Homma S (2016) Role of echocardiography in patients with stroke. J Cardiol 68:91-99.

9. Adams HP, Bendixen BH, Kappelle LJ, et al (1993) Classification of subtype of acute ischemic stroke. Definitions for use in a multicenter clinical trial. TOAST. Trial of ORG 10172 in Acute Stroke Treatment. Stroke 24:35-41.

10. Choi JY, Cha J, Jung JM, et al (2020) Left ventricular wall motion abnormality is associated with cryptogenic stroke. Int J Stroke 15:188-196.

11. Omran SS, Chaker S, Lerario MP, et al (2020) Relationship between Lambl's excrescences and embolic stroke of undetermined source. Eur Stroke J 5:169-173.

12. Kamel H, Healey JS (2017) Cardioembolic Stroke. Circ Res 120:514-526. 
13. Amarenco P, Davis S, Jones EF, et al (2014) Clopidogrel Plus Aspirin Versus Warfarin in Patients With Stroke and Aortic Arch Plaques. Stroke 45:1248-1257.

14. Kent DM, Ruthazer R, Weimar C, et al (2013) An index to identify stroke-related vs incidental patent foramen ovale in cryptogenic stroke. Neurology 81:619-625.

15. Sondergaard L, Kasner SE, Rhodes JF, et al (2017) Patent Foramen Ovale Closure or Antiplatelet Therapy for Cryptogenic Stroke. N Engl J Med 377:1033-1042.

16. Saver JL, Carrol JD, Thaler DE, et al (2017) Long-Term Outcomes of Patent Foramen Ovale or Medical Therapy after Stroke. N Engl J Med 377:1022-1032.

17. Mas JL, Derumeaux B, Guillon E, et al (2017) Patent Foramen Ovale Closure or Anticoagulation vs. Antiplatelets after Stroke. N Engl J Med 377:1011-1021.

18. Prefasi D, Martinez-Sanchez P, Fuentes B, et al (2016) Severity and outcomes according to stroke etiology in patients under 50 years of age with ischemic stroke. J Thromb and Thrombolysis 42:272282.

19. Kim BJ, Sohn H, Sun BJ, et al (2013) Imaging Characteristics of Ischemic Strokes Related to Patent Foramen Ovale. Stroke 44:3350-3356.

20. Schnieder M, Siddiqui T, Karch A, et al (2017) Clinical Relevance of Patent Foramen Ovale and Atrial Septum Aneurysm in Stroke: Findings of a Single-Center Cross-Sectional Study. Eur Neurol 78:264269.

21. Furlan AJ, Reisman M, Massaro J, et al (2012) Closure or Medical Therapy for Cryptogenic Stroke with Patent Foramen Ovale. N Engl J Med 366:991-999.

22. Meier B, Kalesan B, Mattle HP, et al (2013) Percutaneous Closure of Patent Foramen Ovale in Cryptogenic Embolism. New Engl J Med 368:1083-1091.

23. Cabell CH, Pond KK, Peterson GE, et al (2001) The risk of stroke and death in patients with aortic and mitral valve endocarditis. American Heart Journal 142:72-80.

24. Marino B, Jaiswal A, Goldbarg S, et al (2016) Impact of transesophageal echocardiography on clinical management of patients over age 50 with cryptogenic stroke and normal transthoracic echocardiogram. J Hosp Med 11:95-98.

25. EAFT (European Atrial Fibrillation Trial) Study Group (1993) Secondary prevention in non-rheumatic atrial fibrillation after transient ischaemic attack or minor stroke. Lancet 342:1255-1262.

26. Hilberath JN, Oakes DA, Shernan SK, et al (2010) Safety of transesophageal echocardiography. J Am Soc Echocardiogr 23:1115-1127.

27. Zito C, Dattilo G, Oreto G, et al (2009) Patent foramen ovale: comparison among diagnostic strategies in cryptogenic stroke and migraine. Echocardiography 26:495-502.

\section{Figures}




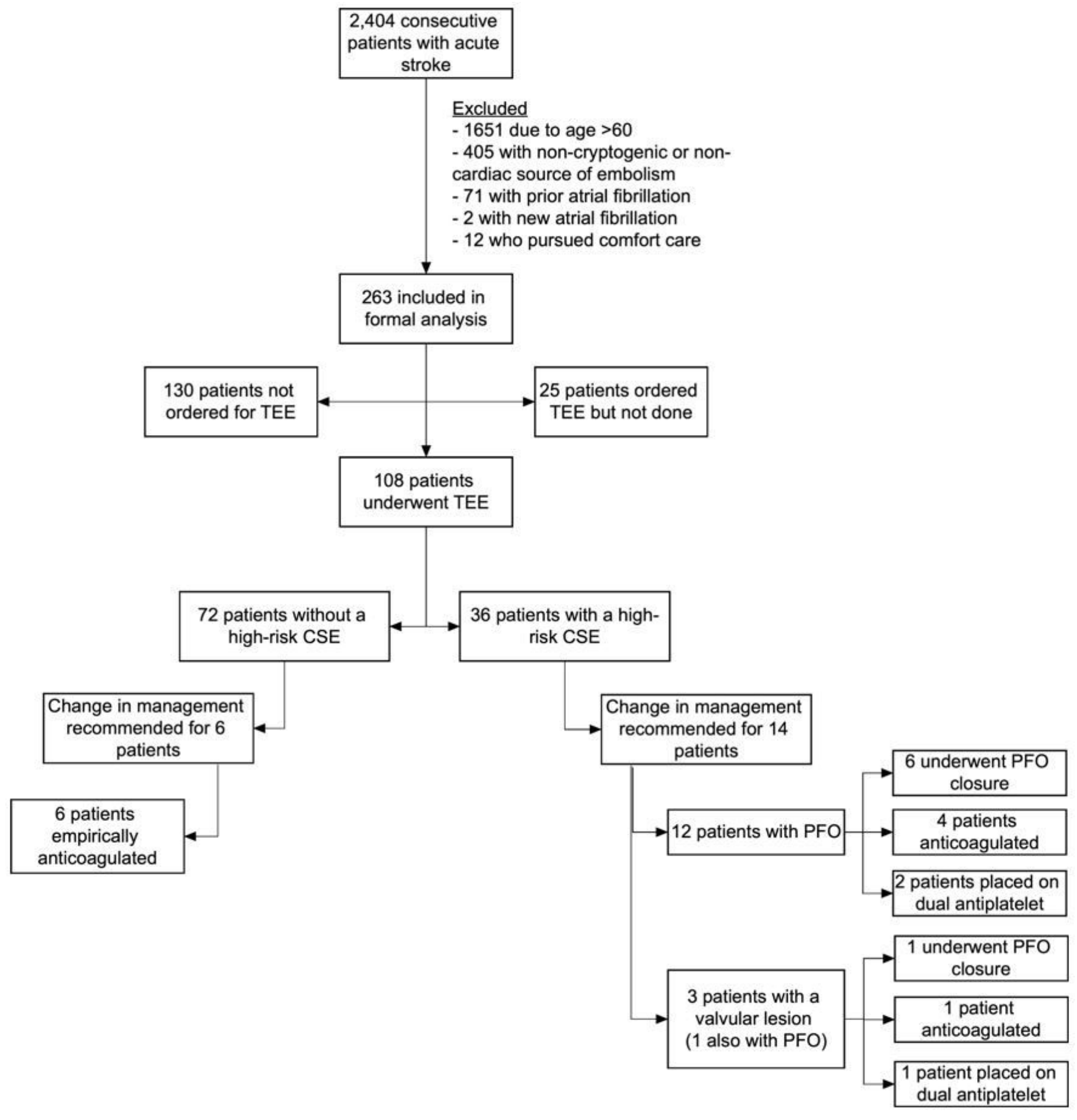

\section{Figure 1}

Patient flowchart. TEE denotes transesophageal echocardiography, CSE cardiac source of embolism, and PFO patent foramen ovale. 


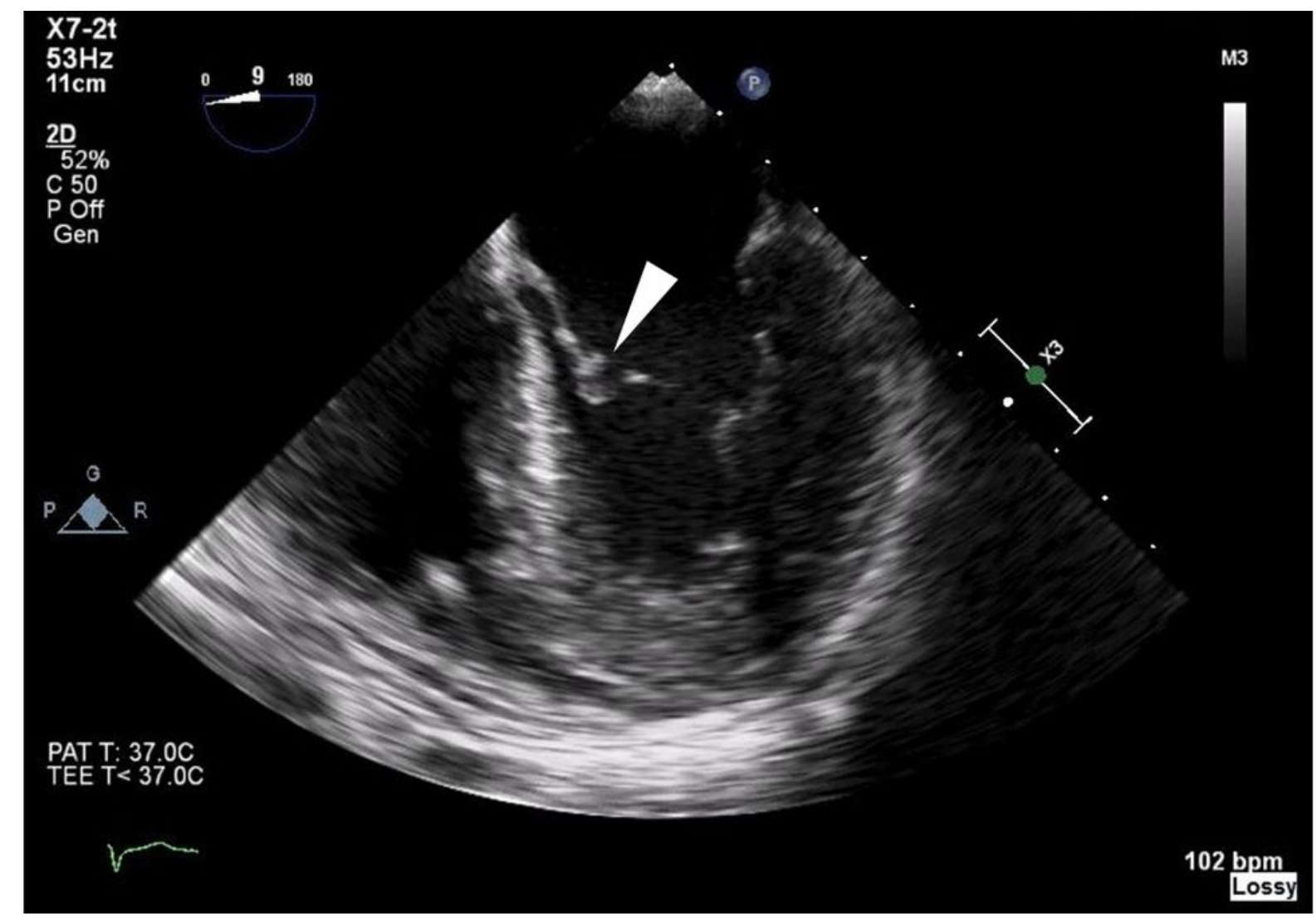

Figure 2

Representative image of an apical four-chamber view demonstrating an $8 \mathrm{~mm}$ non-mobile echobright density on the ventricular surface of the mitral valve anterior leaflet (arrowhead), indicative of endocarditis 


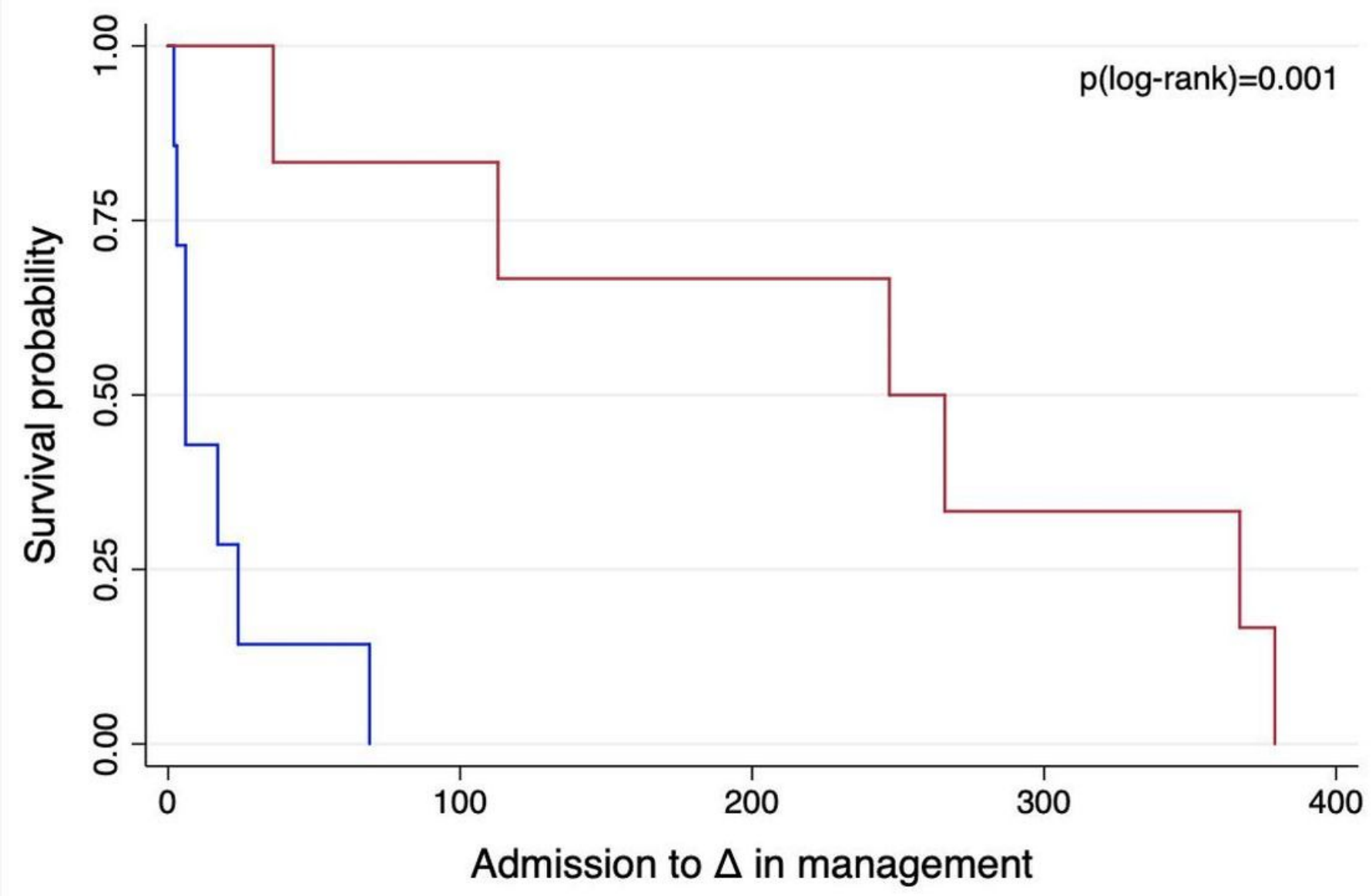

Other $\Delta$ in management

PFO closure

Figure 3

Time to management change in patients with high-risk CSEs. CSE denotes cardiac source of embolism, and PFO patent foramen ovale.

\section{Supplementary Files}

This is a list of supplementary files associated with this preprint. Click to download.

- SupplementaryTable1234.docx 